Article

\title{
Energy Consumption in Public Buildings: The Determinants of Occupants' Behavior
}

\author{
Akvile Cibinskiene * ${ }^{*}$, Daiva Dumciuviene $\mathbb{D}$ and Meda Andrijauskiene $\mathbb{}$ \\ School of Economics and Business, Kaunas University of Technology, LT-44239 Kaunas, Lithuania; \\ daiva.dumciuviene@ktu.lt (D.D.); meda.andrijauskiene@ktu.lt (M.A.) \\ * Correspondence: akvile.cibinskiene@ktu.lt
}

Received: 22 May 2020; Accepted: 8 July 2020; Published: 11 July 2020

\begin{abstract}
Considering the critical amount of power consumption in public buildings, sustainable energy use in the workplace can present an opportunity to tackle the worldwide problem of climate change. A systematic literature review revealed that, though the majority of scientific papers emphasize the importance of appliances and new technologies, human behavior in this area is not less significant. It can contribute to the reduction of energy use and $\mathrm{CO}_{2}$ emissions and address a number of environmental issues. The main purpose of this work is to analyze and compare the research performed on the topic of the determinants of sustainable energy consumption and investigate their impacts on the behavior of employees in three public buildings in Greece. The questionnaire survey discloses that, despite the organizations paying the bill, the employees believe that saving energy at work is important. The results also show that female employees feel more responsible for energy problems, such as the exhaustion of energy sources or global warming. Finally, a regression analysis affirms that the willingness to save a substantial amount of energy at the workplace is greater when employees have higher personal norms, that is, they feel morally obliged to consider the environment and nature in their daily behavior.
\end{abstract}

Keywords: sustainable energy consumption; energy saving; energy saving behavior; determinants; public buildings; office buildings; commercial buildings; intervention

\section{Introduction}

Climate change, increasing $\mathrm{CO}_{2}$ emissions, and diminishing fossil energy resources have become increasingly concerning in recent years. To mitigate climate change impacts, international environmental standards and other formal environmental strategies have been created to balance industrial growth and the safeguarding of the natural environment [1].

Research conducted in different countries highlights the importance of public and private sector organizations in reducing $\mathrm{CO}_{2}$ emissions. Saving energy in the workplace is both a significant challenge and an important opportunity given that building stock consumes approximately $30-40 \%$ of the energy produced worldwide [2,3] and is responsible for approximately one-third of the total greenhouse gas emissions (GHGs).

Research conducted in the United Kingdom and USA has provided quantitative data about $\mathrm{CO}_{2}$ emissions and energy and electricity consumption in public buildings. The operation of non-domestic buildings contributes to around $18 \%$ of the United Kingdom's total $\mathrm{CO}_{2}$ emissions, with $10 \%$ being generated by large public and private sector organizations [4]. In U.K. offices, $55 \%$ of energy is consumed through heating, ventilation, and air-conditioning; $17 \%$ is consumed through lighting; and the remainder is consumed through equipment, food preparation, and refrigeration [5]. Commercial buildings consume at least $18 \%$ of the total electrical energy used in the United States [6], and over $\$ 2.8$ billion is wasted every year owing to computers being left on during the night and on the weekends [7]. 
The data and research in Europe demonstrate similar results in terms of energy wastage in commercial buildings. A field trial on individual energy use in offices [8] showed that energy use in office computing has contributed approximately $30 \%$ of the energy demand in the European service sector over the last decade. Complimentary research by Mulville, Jones, and Huebner [9] found that a significant amount of IT office equipment is underutilized and left on overnight. Masoso and Grobler [10] found that $56 \%$ of the total energy used in office buildings is consumed during non-working hours simply because occupants leave lighting and equipment on at the end of the day.

Thus, there is high potential to save energy by changing the use of environmental controls by occupants [11]. Salleh, Kandar, and Sakip [12]; Schleich [13]; and Yun [14] stated that energy consumption in public and commercial buildings may be reduced by up to $30-40 \%$ by behavioral change. Katzeff, Broms, Jönsson, Westholmm, and Räsänen [15] emphasized the high potential of energy saving in the working place given the sizes of offices. In addition to the high potential for energy saving behavior in public buildings, some barriers have also been listed in previous studies conducted. The most often-mentioned barrier to energy saving in workplaces is the lack of financial benefit from energy saving - the bill is paid by the employer, not by the office worker [5,15-19]. Jáñez Morán et al. [20] emphasized the fact that the biggest barrier to the implementation of energy efficiency measures in public buildings is that the people involved in energy consumption are not the same people who benefit financially from energy savings. The other often-mentioned issues related to energy saving behavior in public buildings are the different behaviors of individuals inside the organization, the individual comfort level needed for the workers, devices that are shared by multiple employees, and the possibility of switching off appliances [5,15,17].

Yan, Hong, Dong, Mahdavi, D'Oca, Gaetani, and Feng [21] stress that energy savings from behavioral changes may not be sustained because of the rebound effect or other factors. Therefore, the prediction of whether the promoted energy saving behavior will be sustained and for how long it will stay is complicated.

The other relevant issue that has been raised is an energy performance gap [22]. It is defined as "the discrepancy between the simulation-predicted and the realized energy savings after buildings become green certified" (p. 364, [22]). Scholars found out that, despite the latest technologies, the energy consumption in "green buildings" does not decrease to the predicted levels. The analysis of an energy performance gap revealed that the occupant behavior is equally important to engineering and organizational factors. As current energy modeling approaches weakly represent the contextual processes that lead occupants to link their behavior to their working or living environments, there is a high importance of the cooperation between the technical and behavioral dimensions of energy use [21-24]. Scholars claim that it might become very beneficial for energy saving solutions. It must be noted that, although general behavioral models have been developed and extensively used from the last century, only recently has more attention been paid to human behavior towards energy saving [25-29].

The reviewed scientific literature suggests that the vast majority of previous research conducted on efficient energy consumption behavior issues has focused on residential buildings [8,17,19,30-33]. Lo, Peters, and Kok [34] highlighted that there is a lack of research on the pro-environmental behavior of general employees in organizations. Existing research on energy use in commercial and public buildings often underlines the implementation of technological measures for energy saving in public buildings, paying less attention to the potential for behavioral change [35]. Therefore, a more detailed investigation of factors influencing human behavior in terms of energy saving in commercial and public buildings is needed.

Although many studies have been conducted on the determinants, strategies, and interventions of household energy consumption, much less is known about energy behavior in public buildings. In this study, a systematic literature review was conducted for public buildings. On the basis of the results of the literature review, two questionnaire surveys-one at baseline and after one year-were conducted in order to check the validity of the results. The objective of this paper was to investigate 
and systematize the determinants of energy consumption behavior in public buildings and to check their importance using a Greek public buildings case.

\section{Materials and Methods}

This paper contains both a systematic literature review and an empirical part based on a correlation and regression analysis of the results from the questionnaire survey.

\subsection{Literature Review}

The literature review was conducted using a systematic literature review methodology [36]. A systematic review is a type of literature review that uses systematic methods to collect secondary data, critically appraise research studies, and synthesize findings qualitatively or quantitatively [37]. This method enabled us to summarize the current research and results regarding sustainable energy consumption in public buildings.

A systematic literature review identifies, selects, and critically appraises research in order to answer a clearly formulated question [38].

A research question was operationalized into the following set of search terms presented in Table 1. Search terms used in the literature review of determinants of energy consumption in public buildings. Because increasing interest in scientific papers on energy saving behavior in the public sector has been observed since 2000, only studies published after 2000 were included. The query was restricted to a search of the titles, abstracts, and keywords (ScienceDirect, EBSCO (EconLit, GreenFile), Emerald). The search of the databases Web of Science and Scopus, on the other hand, was restricted to a search of the titles.

Table 1. Search terms used in the literature review of determinants of energy consumption in public buildings.

\begin{tabular}{cc}
\hline Topic & Search Terms \\
\hline Energy consumption & $\begin{array}{c}\text { (energy OR electricity) AND ((consumption OR efficiency OR saving OR } \\
\text { conservation OR reduction) OR "energy use" OR "electricity use") AND behave } \\
\text { workplace OR office visitor OR "public building" OR service OR company OR } \\
\text { building OR employee" OR worker }\end{array}$ \\
$\begin{array}{c}\text { Public building } \\
\text { Determinants }\end{array}$ & $\begin{array}{c}\text { OR habit OR norm } \\
\text { Intervention }\end{array}$ \\
intervention OR program OR campaign
\end{tabular}

The search results were either included or excluded based on the title (first round) and abstract (second round). A summary of the search and selection process and main reasons for rejection are provided in Table 2.

Out of the 471 search results, 45 studies were selected for the review (9.55\% acceptance rate). The flow diagram of the search is depicted in Figure 1. The low acceptance rate indicates that the impact of behavior in public buildings still lacks a deeper level of scientific research. 
Table 2. Summary of search and selection process (public buildings).

\begin{tabular}{cc}
\hline Characteristic & No. of Papers \\
\hline $\begin{array}{c}\text { Studies found } \\
\text { Accepted }\end{array}$ & 471 \\
Main reasons for rejection: & 45 \\
Outside of scope & 164 \\
Residential building studies & 104 \\
Other sectors (e.g., travel, transport, tourism, culinary, healthcare) & 38 \\
emissions, and so on (data-driven, no focus on occupants) & 30 \\
Building-related energy consumption, efficiency measures, renovation opportunities, & 18 \\
Scope too broad (sustainability, pro-environmental behavior, climate change) & 11 \\
Policy and regulations & 7 \\
Non-empirical (e.g., review, comment, essay) & 8 \\
Focus on models and algorithms (e.g., modelling of energy-efficiency of building when & 4 \\
changing specific parameters or taking certain measures) & Other resources (e.g., water, waste management)
\end{tabular}

Source: own elaboration.

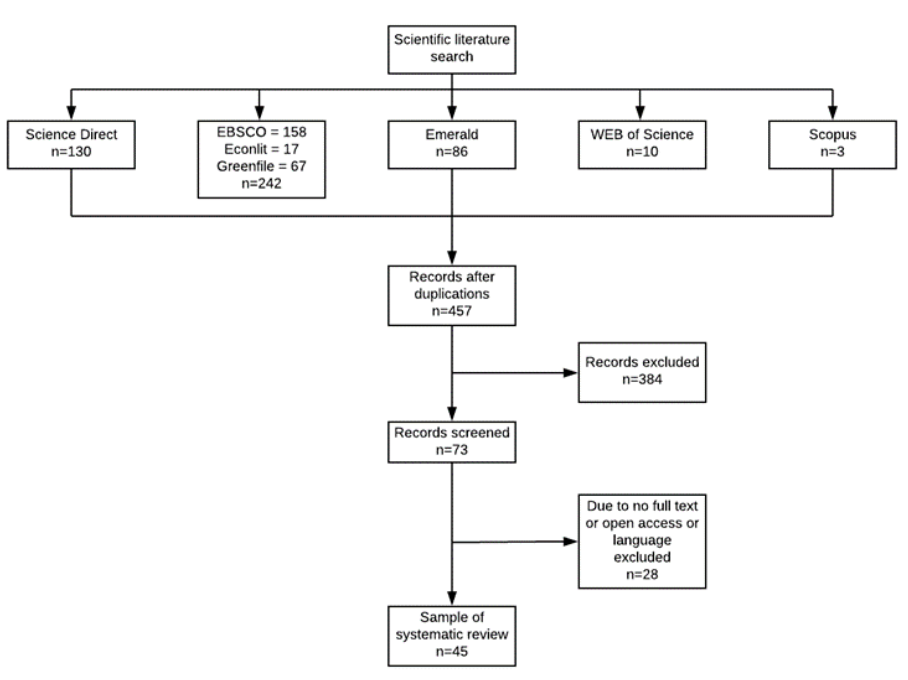

Figure 1. Flow diagram of the review process. Source: own elaboration.

The number of studies collected by year revealed that the interest in sustainable energy consumption in public buildings has peaked in recent years (especially from 2012 to 2015). Studies of energy consumption behavior in the public buildings have mainly focused on employees or office workers in general, while less attention has been paid to building managers, and only one study focused on visitors. Selected studies focused on different types of office workers, for example, administrative staff or managers (for the main characteristics of target groups, see Table 3).

A review with a particular focus on the role of visitors might yield some exploratory findings about visitors, but it is apparent that their role has rarely been considered in energy-saving studies. Whether this is just an oversight or a lack of significance or influence of visitors on a given building's energy use is yet to be investigated, but this is beyond the scope of the literature review conducted here.

The vast number of different scientific journals that have published the reviewed papers shows that the topic analyzed is relevant and has been studied from different points of view (publishing journals varied from "Energy and Buildings", "Energy Policy", and "Building \& Environment" to "Applied Psychology", "Journal of Business Ethics", and "Human Ecology"). 
Table 3. Target groups assessed in public buildings.

\begin{tabular}{cc}
\hline Target Groups & Number of Papers Involving the Target Group \\
\hline Employees/office workers & 30 \\
Senior managers & 1 \\
Administrative employees & 1 \\
Staff members & 1 \\
Building managers & 3 \\
Building visitors & 1 \\
All associated with the building & 3 (not included in other total numbers) \\
N/A & 2 \\
Students & 3 \\
\hline
\end{tabular}

Source: own elaboration.

The regional distribution of empirical data reviewed showed that most studies on sustainable energy consumption in public buildings were conducted in Western European countries (55\%), North America (23\%), and Asia (20\%). The majority of empirical studies on energy saving in public buildings have been conducted in the United Kingdom (13) and USA (8). Other studies were done in China (4), the Netherlands (3), Canada (2), the EU (2), Germany (2), Portugal (2), Sweden (2), Australia (1), Cyprus (1), Iran (1), South Korea (1), Malaysia (1), and Taiwan (1). One study presented research that was done in several regions: the USA, Europe, China, and Asia-Pacific. An increasing interest in research on energy saving behavior in public buildings was noticed and this issue has been more commonly investigated in developed countries (such as the USA and Europe) rather than less-developed ones.

There is evidence that occupants' energy use represents a large fraction of the total energy consumed in public buildings. Energy saving in public buildings can be achieved by changing occupants' behavior and applying effective interventions. It is important to identify any evidence on the impact on occupants' energy consumption and saving behaviors.

Frederiks, Stenner, and Hobman [39] classified various individual (socio-demographic and psychological) and situational (contextual and structural) factors that may influence residential energy saving. Having assessed the peculiarities of energy consumption in public buildings, we adopted a classification of determinants in public buildings (Figure 2).

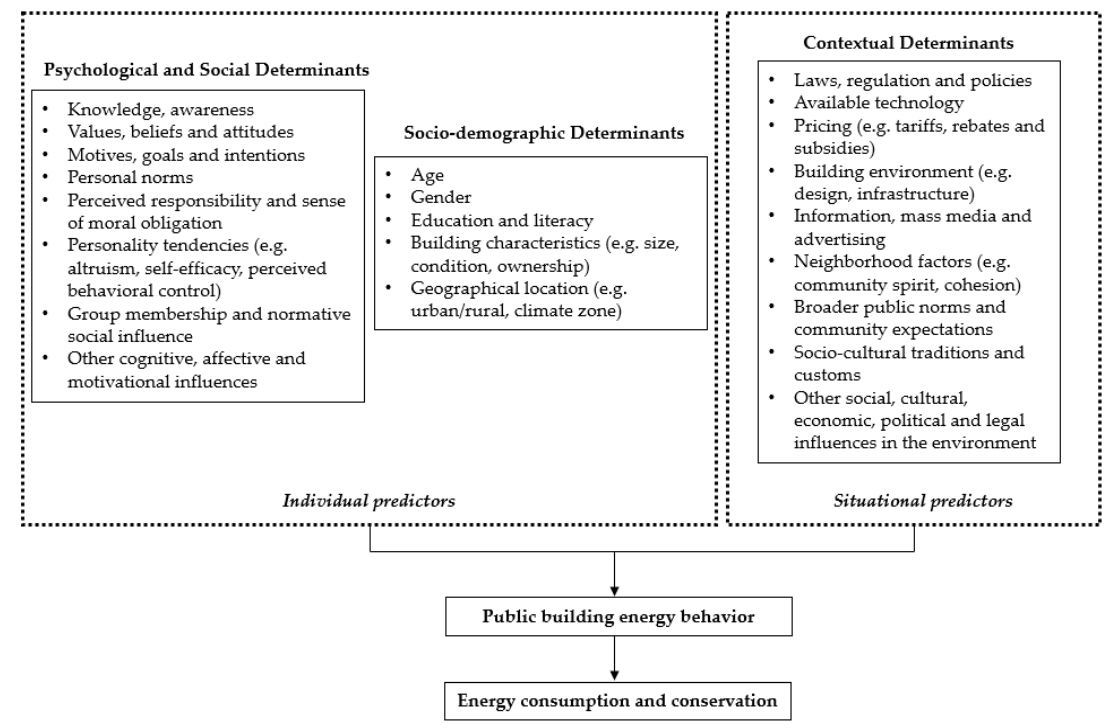

Figure 2. Determinants that may influence energy-saving behavior in public buildings. Adapted for public buildings in accordance with Frederiks, Stenner, and Hobman [39]. 
After a comprehensive analysis of energy consumption determinants, they were sorted into three groups: psychological and social determinants, sociodemographic determinants, and contextual determinants. All of these determinants can affect and be important for the behavior of occupants in public buildings, and may finally have an impact on the efficient use of energy.

\subsection{Questionnaire Survey}

Though different methods are applied to investigate the behavioral impact on energy consumption in public and office buildings (e.g., case studies, interviews, benchmark analyses), about one-third of the reviewed papers $[11,19,31,40-47]$ applied questionnaire surveys.

Therefore, two questionnaires-a baseline questionnaire in October 2018 and an evaluation questionnaire in October 2019-were organized. The 47 respondents were the employees of three different Greek public institutions belonging to the pilot sites of the project "enCOMPASS-Collaborative Recommendations and Adaptive Control for Personalized Energy Saving" (funded by the EU H2020 Programme, grant agreement no. 723059). The pilot sites-a documentation center, office headquarters, and a retail store-were equipped with the sensor infrastructure and introduced the enCOMPASS application (app). The particular app not only helps with raising awareness about energy-related matters, but also initiates new energy saving behaviors. Throughout the intervention period, the employees of the earlier specified public buildings were encouraged to think about energy saving more often than before through energy-saving tips and recommendations. They were also able to see the current consumption of the building and compare it to the energy saving goal. Finally, the participants of the trial were rewarded for their efforts with a number of motivational elements (e.g., badges, wandering trophies).

The baseline and evaluation questionnaire surveys were both conducted to find out how attitudes, awareness, knowledge, and social and subjective norms (the most important determinants of energy saving in public buildings, according to the literature review) affect occupants' behavioral intentions to save energy. The responses of survey participants also allowed us to estimate how the below-mentioned constructs changed owing to the usage of the enCOMPASS app:

- Attitudes, awareness, social norms (following [34,48-51]). User awareness of energy consumption is a complex attitude formation process that involves understanding how individual behavior as well as the influences of other people (e.g., superiors, co-workers) impact energy consumption. Constructs include the ascription of responsibility, perceived personal (social) norms, perceived subjective norms, and the energy-saving-comfort trade-off.

- Knowledge In order to measure the increase in the knowledge of energy-saving actions, the individual capabilities described in the integrated model of pro-environmental behavior of Stern [52] were used. An increase in the knowledge of energy-saving actions was reflected in an increase in the belief about the personal capability to save energy and the increase in the degree of environmental knowledge. Constructs related to the knowledge of energy saving actions include environmental knowledge and perceived behavioral control.

- Intention to save energy It was expected that the incentives provided through enCOMPASS would become contextual forces that can increase the awareness of the consequences of energy saving as well as affect conservation behavior directly. As a norm, the formation process underlies the behavior change process, and broader social norms can play an important role in influencing awareness and the intention to save energy. The construct related to the intention to save energy is the intention to save energy.

- Basic demographics For example, gender, age, and educational level.

Instruments were composed of multiple items, using Likert scales or semantic differentials. The statistical analysis was conducted using SPSS (Statistical Package for the Social Sciences).

Firstly, we compared means of the results generated during the first (baseline) and second (evaluation) surveys. Secondly, we generated Spearman's correlations of variables with respect to 
the respondents' energy-saving behaviors, attitudes, habits, and their sociodemographic features, such as age, gender, and education level. Thirdly, we carried out a regression analysis in order to model and analyze the relationship between a respondent's willingness to try to save a substantial amount of energy in their workplace over the following three months (a dependent variable) and six independent variables: (i) ascription of responsibility, (ii) personal norms, (iii) perceived behavioral control, (iv) energy knowledge, (v) subjective norms, and (vi) the energy-saving-comfort trade-off.

\section{Sustainable Energy Consumption Determinants in Public Buildings}

\subsection{Psychological and Social Determinants}

Analyses of energy consumption and conservation have covered the explanations, predictions, and changes in consumers' behaviors. Among others, psychological and social factors have been studied intensively in order to explain differences between individuals with respect to energy consumption and energy conservation behavior.

Psychological determinants of energy consumption are related to human psychology. Examples of psychological determinants are knowledge, awareness, beliefs, attitudes, motives, intentions, perceived behavioral control, personal norms, and subjective norms.

Psychological and social determinants have mainly been analyzed in office buildings ( 26 papers) and public buildings (6 papers). The most frequently studied target group in office buildings has been office workers ( 21 papers), whereas all persons associated with the building were the focus of two papers. One paper analyzed senior and building managers and two papers investigated building managers together with office workers and/or technicians. Office and administrative staff were the focus of five papers, and one of them additionally included building managers in the study. Three papers investigated all types of buildings by analyzing the responses of students.

Thirty-six out of the 45 papers studied analyzed the psychological and social determinants of energy consumption, and 39 different determinants were identified (see Table 4). Attitudes (18 papers), awareness (6 papers), social norms (6 papers), knowledge (4 papers), motivation (4 papers), and subjective norms (4 papers) were the most frequently studied determinants.

Table 4. Psychological and social determinants in public buildings.

\begin{tabular}{cc}
\hline Determinant & References \\
\hline Attitudes & {$[16,17,30-32,34,41,43-46,53-59]$} \\
Awareness & {$[14,33,34,60,61]$} \\
Social norms & {$[17,20,32,45,57,62]$} \\
Knowledge & {$[20,54,55,63]$} \\
Motivation & {$[20,42,64,65]$} \\
Subjective norms & {$[24,30,53,58]$} \\
\hline
\end{tabular}

Source: own elaboration.

With their research on attitudes and motivation towards energy conservation, Jurin and Fox-Parrish [54] found four principle dimensions that affected how people think about the conservation of energy, namely, comfort and health, high effort-low payoff, the role of individual consumers, and the legitimacy of the energy problem.

Stokes, Mildenberger, and Savan and Kolenda [53] presented research in which behavioral determinants were defined as internal versus external barriers. They applied the theory of planned behavior to create ten different barrier subcategories. They focused on the individuals' beliefs about which factors support or inhibit behavior.

Motivation to overcome energy efficiency barriers in terms of limited resources, either human or financial, as a determinant for energy consumption, were studied by Henriques and Catarino [66]. Jáñez Morán et al. [20] linked motivation to the level of knowledge. In the analyzed research, knowledge 
is presented as being effective in both government and business outreach programs and energy conservation education in elementary schools [54,63]. Lee, Lin, Guu, Chang, and Lai [55] argued that knowledge needs to be linked to action in teaching and learning, and the reflection of knowledge on attitudes and responsible behavior is important.

Tetlow, et.al [45] pointed out that habit is a crucial determinant in energy-related behavior and defined social determinants as being important for psychology, which could potentially drive energy use. Values, beliefs, and intentions were analyzed as important predictors of individual determinants on pro-environmental behavior and important determinants acting in a network with other occupants [44].

Metzger, Kandt, and VanGeet [62] argued that competition is important for the development of social norms. As a way to receive information about one another's behaviors and raise people's awareness of the opportunities for the reduction of energy consumption, feedback about energy consumption was analyzed by Handgraaf, Van Lidth de Jeude, and Appelt [42] and Nilsson, Andersson, and Bergstad [17]. A number of the contributing authors mentioned below discussed organizational factors in terms of energy saving and pro-environmental behavior. Emphasis was placed on the relationship between having an organizational focus and pro-environmental behavior [34], an organizational electricity-saving climate [19], and an organizational culture [34]. Organizational determinants (organizational focus, organizational structure, organizational/site type and size, departmental type and size, organizational culture) were analyzed as a whole by Lo et al. [34], while organizational electricity saving was studied by Zhang et al. [19]. Perceptions of organizations' incentives and support were studied by Manika, Wells, Gregory-Smith, and Gentry [56], underlining that general environmentally friendly attitudes might influence perceptions of an organization's incentives and support. People factors (occupants' behaviors and maintenance factors, indoor temperature set point) were introduced and analyzed by Chung and Hui [67] emphasizing how people determine energy use through systems operation (switching on/off appliances). Zierler et al. [33] focused on energy intentions, self-appraisal, self-efficacy, energy awareness, goal flexibility, and technology awareness in their study about the energy efficacy behavior of individuals in large organizations.

Lokhorst et al. [43] studied perceived behavioral control, emphasizing commitment combined with feedback as useful interventions that attract employees to the process. Changes in the energy-use behavior and attitudes of employees should be considered coherent options for cost-effective energy saving [31]. The use of games as a tool for engagement was presented in research by Tolias et al. [60], in the sense that competitions could be introduced with the aim of increasing engagement among employees. Feedback (public and private) was studied by Handgraaf et al. [42], where the authors underlined that, in order to have more effective feedback, acknowledgement is important.

To sum up, energy consumption and conservation in public buildings are associated with a wide range of psychological and social variables that can facilitate or undermine the intrinsic motivation to save energy.

\subsection{Sociodemographic Determinants}

The concept "sociodemographics" refers to the definition of a group according to its sociological and demographic characteristics. Sociodemographic determinants include age, gender, education and literacy, employment status, socioeconomic status and income, dwelling characteristics, and geographical location.

Sociodemographic determinants have been studied in public buildings (eight papers). Four of these papers focused on different human groups-all persons associated with the building, office workers, building managers, and office buildings in general-but not on any type of employee. There were also two studies where the focus was on the buildings, but not the employees. These studies were conducted in public and social buildings as well as in small and medium enterprises. The studies by Henriques and Catarino [66], Li et al. [68], and Schleich and Gruber [69] involved all persons associated with the building, while office workers took part in the research by Zierler et al. [33]. Data 
analysis from EU pilot projects was done by Jáñez Morán et al. [20], where the target group included users and visitors.

In total, eight papers analyzed sociodemographic determinants of energy consumption, and 15 different determinants were identified in these papers. The climate was studied in two papers, and the rest of the determinants were analyzed once each in separate papers (see Table 5).

Table 5. Sociodemographic determinants in public buildings.

\begin{tabular}{cc}
\hline Determinant & References \\
\hline Climate & {$[67-69]$} \\
Quality of social interaction and communication & {$[20]$} \\
Building type factors & {$[67]$} \\
Risk and uncertainty & {$[13]$} \\
Lack of time to improve energy efficiency & {$[69]$} \\
Split incentives and appropriability & {$[13]$} \\
Benefit evaluation & {$[33]$} \\
Hidden costs & {$[13]$} \\
Access to capital & {$[13]$} \\
Building size & {$[66]$} \\
Investor/user dilemma & {$[68]$} \\
Operation and maintenance & {$[69]$} \\
Efficient technologies & {$[68]$} \\
Motivation to overcome energy efficiency barriers & {$[68]$} \\
Snvestments for energy efficiency in buildings & {$[59]$} \\
\hline
\end{tabular}

A more detailed analysis of studied determinants by individual authors is presented as well. Building type factors, occupancy factors (floor area, operational schedule, and the number of employees), climate factors, energy end-use factors (chiller equipment type, air side distribution type, air side control, water side distribution control, lighting equipment, lighting control, and office equipment) were studied in a benchmark study conducted by Chung and Hui [67]. Climate factors and building size were also included in studies by Li et al. [68] and Chung and Hui [67].

Time (lack of time to analyze the potential for improving energy efficiency) and type of ownership (investor/user dilemma) were defined as two of the most important barriers to improving energy efficiency in companies [69]. Schleich and Gruber (p. 454, [69]), in their study, argued that "If a company is renting office space, neither the landlord, nor the company (tenant) may have an incentive to invest in energy efficiency because the investor cannot appropriate the energy cost savings. On the one hand, the landlord will not invest in energy efficiency if the investment costs cannot be passed on to the tenant, who will benefit from the investment through lower energy costs." A lack of time to improve energy efficiency was introduced as a determinant of energy saving by Schleich and Gruber [69]. It was not defined directly, but was analyzed in terms of a lack of time to analyze the potential for energy efficiency. Hidden costs (e.g., general overhead costs of energy management), access to capital, risk and uncertainty (defined as a possible financial risk, for example, regulatory risk, fluctuation of energy prices), split incentives, and appropriability (landlord/tenant or user/investor dilemma) were investigated by Schleich [13]. Jáñez Morán et al. [20] emphasized that social interactions represent an effective tool for energy saving.

All in all, scholars have proved that sociodemographic characteristics are important for the analysis of energy consumption and saving.

\subsection{Contextual Determinants}

An individual's personality can be described and understood in terms of various contexts in which that individual is embedded. The contextual determinants take both personal factors as well as daily activities in the individuals' environment into account and can be defined in different contexts: historical, 
cultural, developmental, and interpersonal. Contextual determinants of energy saving describe different norms and restrictions, such as laws, regulations and policies, and building characteristics.

Nine papers focused on the contextual determinants of energy consumption, and 12 different determinants were highlighted. It can be noted that the determinant "lack of information about energy consumption" is part of the wider meaning of the determinant "imperfect information". Definitions of contextual determinants of energy consumption behavior in public buildings that have been determined in the literature and measurements that have been used to assess determinants are presented in Table 6 .

Table 6. Contextual determinants in public buildings.

\begin{tabular}{cc}
\hline Determinant & References \\
\hline Environmental norms & {$[33]$} \\
Technology adoption norms & {$[33]$} \\
Technological frustration & {$[33]$} \\
Lack of information about energy consumption & {$[69]$} \\
Imperfect information & {$[13]$} \\
Occupancy factors & {$[67]$} \\
Energy end use factors & {$[67]$} \\
Window opening and closing & {$[70]$} \\
Company policy & {$[40]$} \\
Activity-based & {$[71]$} \\
ICT (Information and communications technology) support & {$[20]$} \\
Awareness of governmental regulations & {$[61]$} \\
\hline
\end{tabular}

Source: own elaboration.

ICT solutions were discussed in the research by Jáñez Morán et al. [20] as an important factor in energy management and resource integration in terms of energy efficiency. They also presented ways in which information about energy efficiency in a building could reach employees. Information (lack of information about energy consumption patterns in different types of companies) was defined as one of the most important barriers to improving energy efficiency in companies [69]. Metzger et al. [62] identified that the provision of information about energy saving to employees can lead to a higher level of awareness, but does not necessarily influence behavior: "The control system had significantly higher energy and cost savings compared to behavioral change methods" (p. 7, [62]).

According to Zhuang and $\mathrm{Wu}$ [61], the awareness of governmental rules is a necessary, but insufficient condition for behavior change. Fabi et al. [70] studied window opening and closing and emphasized the dynamics of the relationships among the indoor environment, occupant behavior, and energy consumption. These factors are important for developing the behavioral models of occupants. Research by Agha-Hossein et al. (p. 122, [40]) showed that "Disempowering employees in terms of reducing their control over their environment helped the company to save energy without having a significant negative impact on employees' satisfaction and productivity". However, Goulden and Spence (p. 286, [71]) pointed out that "maximizing energy efficiency within workplaces requires that the task of energy reduction would go to all building users".

Zierler et al. (p. 43, [33]) pointed out the environmental norms (how satisfied respondents were with the organization's handling of environmental issues and with the overall level of information they are able to access), technology adoption norms (impression of how easily other parts of the organization have adopted new technologies in general and the organizational support available for necessary adaptations), and technological frustration (difficulty with learning about new technologies and conflicts between performance goals) as important energy saving determinants in public buildings.

While the majority of the studies of contextual determinants focused on office workers in office buildings (seven papers), all persons associated with the respective building were involved (one paper that analyzed commercial and service buildings), including office workers, employees, building managers, and senior managers, and others were considered only in one paper reviewed. One study 
focused on the building occupants, and the other study conducted in public and social buildings analyzed buildings as a whole, but did not focus on the type of employees. One study focused on any type of building, analyzing students as a target group.

It can be concluded that contextual determinants and the interrelations between them affect individual consumption and saving behavior, a rule that can be applied to energy saving behavior as well. "Environmental norms relate to how satisfied respondents were with the organization's handling of environmental issues, and with the overall level of information they are able to access".

After the investigation of all individual and situational predictors influencing energy saving behavior in public buildings, it can be summarized that the most investigated group of determinants is "psychological and social determinants". On the basis of the number of research studies focusing on the particular determinants, attitudes, awareness, social (personal) norms, knowledge, subjective norms, and motivation were identified as the most relevant determinants.

\section{Results of the Empirical Research}

In terms of the descriptive statistics, $40.43 \%$ of the participants revealed their gender as male, $42.55 \%$ as female $(42.55 \%)$, and $17.02 \%$ of respondents chose the option "I'd rather not say". The majority of respondents belonged to the 31-40 year age group (50.00\%). Others were 21 to 30 (14.58\%), 41-50 $(29.17 \%)$, and $51-60(2.1 \%)$, while 3 out of the 47 participants preferred not to reveal their age.

It should be noted that the participants of the survey were highly educated — the vast majority had a Bachelor's (48.93\%) or Master's (37.17\%) education level. The distribution across different public buildings was spread in the following way: $17.02 \%$ of the respondents worked in a documentation center, $51.06 \%$ of them were employed in an office headquarters, and $31.91 \%$ worked in a retail store.

The literature review revealed that the most important determinants of energy consumption in public buildings were the psychological and social backgrounds. Hence, an empirical study was conducted in order to determine how differently these determinants affect an occupant's behavioral intention to save energy.

Besides the basic demographics (i.e., gender, age, and education level), there were seven different groups of constructs designed for the questionnaire survey: ascription of responsibility (AR); personal norms (PN); subjective norms (SN); energy-saving-comfort trade-off (COMF); self-reported knowledge of energy saving actions (EN); perceived behavioral control (PBC); and behavioral intention to save energy (BI).

The exact questions asked and the comparison of means of the results generated during the first (baseline) and the second (evaluation) surveys are presented in Tables 7-12.

\subsection{Attitudes, Awareness, and Subjective Norms}

The comparison of the results from the baseline and evaluation surveys shows that the overall ascription of responsibility score for the public building employees increased by 0.22 , from 4.1 to 4.32 (see Figure 3).

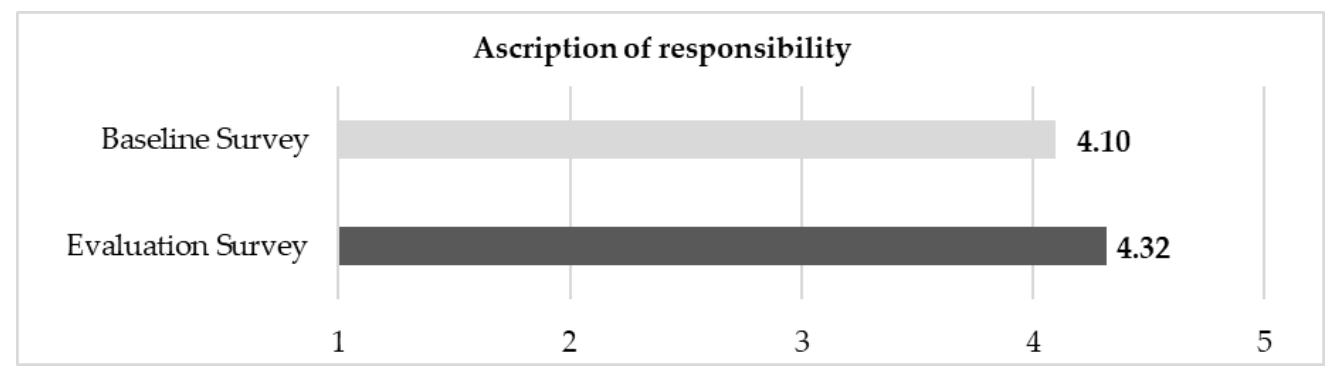

Figure 3. A comparison of ascription of responsibility in Greek public buildings (before and after the trial). 
It can be seen that, from the beginning of the trial, the respondents felt jointly responsible for energy problems, such as the exhaustion of energy sources and global warming. Moreover, even though the organization paid the energy bill, it was stated that saving as much energy as possible is important (during the baseline survey, $80 \%$ of respondents "rather agreed" or "fully agreed" with this statement; during the evaluation survey, $100 \%$ of respondents agreed; see the overall score of 4.70 in Table 7 ).

Table 7. Mean score for the ascription of responsibility (AR) factor (fully disagree (1) to fully agree (5)).

\begin{tabular}{cccc}
\hline Code & Question & Mean (Baseline) & Mean (Evaluation) \\
\hline AR & $\begin{array}{c}\text { Joint responsibility for energy problems } \\
\text { (a composite value) }\end{array}$ & 4.10 & 4.32 \\
AR_1 & $\begin{array}{c}\text { I am jointly responsible for the energy problems } \\
\text { Not only the government and industry are } \\
\text { responsible for high energy consumption levels, } \\
\text { but me too }\end{array}$ & 4.17 & 4.55 \\
AR_3 & I feel jointly responsible for the exhaustion of \\
energy sources & 3.66 & 4.92 & 4.34 \\
AR_4 & $\begin{array}{c}\text { I feel jointly responsible for global warming } \\
\text { Although my organization pays the bill, I feel } \\
\text { that I have to save as much energy as I can }\end{array}$ & 3.92 & 4.34 \\
\hline
\end{tabular}

Table 8. Mean for perceived personal norms (PN) (totally disagree (1) to completely agree (7)).

\begin{tabular}{cccc}
\hline Code & Question & Mean (Baseline) & Mean (Evaluation) \\
\hline PN & Personal norms towards the reduction of & 3.76 & 5.56 \\
PN_1 & I feel morally obliged to save energy & 3.90 & 5.60 \\
PN_2 & I feel guilty if I do not reduce my energy use & 3.40 & 3.87 \\
PN_3 & I feel good if I reduce my energy use & 3.96 & 6.23 \\
PN_4 & I feel obliged to bear the environment and & 3.81 & 6.02 \\
PN_5 & nature in mind in my daily behavior & 3.72 & 6.06 \\
\hline
\end{tabular}

Table 9. Mean perceived subjective norm (SN) scores (totally disagree (1) to completely agree (7)).

\begin{tabular}{cccc}
\hline Code & Question & Mean (Baseline) & Mean (Evaluation) \\
\hline SN & $\begin{array}{c}\text { The influence of superiors, co-workers, and } \\
\text { people in respondents' private lives on the } \\
\text { intention to save energy (a composite value) } \\
\text { My superiors believe that I should save energy } \\
\text { at work }\end{array}$ & 4.26 & 5.32 \\
SN_1 & $\begin{array}{c}\text { My co-workers believe that I should save } \\
\text { energy at work }\end{array}$ & 4.56 & 5.79 \\
SN_2 & $\begin{array}{c}\text { People who are important in my personal life } \\
\text { believe that I should save energy at work }\end{array}$ & 3.71 & 4.55 \\
SN_3 &
\end{tabular}

Table 10. Mean scores for factors related to knowledge on energy consumption (EN) (fully disagree (1) to fully agree (5)).

\begin{tabular}{cccc}
\hline Code & Question & Mean (Baseline) & Mean (Evaluation) \\
\hline EN & $\begin{array}{c}\text { Knowledge about the energy consumption of the } \\
\text { surrounding electrical appliances (a composite value) }\end{array}$ & 3.14 & 3.92 \\
EN_1 & $\begin{array}{c}\text { I know how much energy my laptop or } \\
\text { computer consumes }\end{array}$ & 3.38 & 3.82 \\
EN_2 & I know how much energy the heating system consumes & 3.07 & 3.79 \\
EN_3 & I know how much energy the air conditioning consumes & 3.09 & 3.72 \\
EN_4 & I know how much energy the lights consume & 3.07 & 4.15 \\
\hline
\end{tabular}


Table 11. Mean scores for factors related to perceived behavioral control (PBC) (not at all able to do it (1) to able to do it to a great extent (7)/very little control (1) to complete control (7)).

\begin{tabular}{cccc}
\hline Code & Question & Mean (Baseline) & Mean (Evaluation) \\
\hline PBC & $\begin{array}{c}\text { Perceived behavioral control to limit power } \\
\text { consumption at work (a composite value) } \\
\text { I believe that I am able to avoid unnecessary } \\
\text { pBC_1 }\end{array}$ & 4.85 & 4.01 \\
PBC_2 & $\begin{array}{c}\text { To what extent do you think you are able to } \\
\text { limit the power consumption at work to the } \\
\text { absolutely necessary level? }\end{array}$ & 5.60 & 4.62 \\
PBC_3 & $\begin{array}{c}\text { How much control do you personally feel you } \\
\text { have over the amount of electricity consumed } \\
\text { at work? }\end{array}$ & 3.71 & 2.98 \\
\hline
\end{tabular}

Table 12. Mean score for factors related to behavioral intentions (BI) (totally disagree (1) to completely agree (7)).

\begin{tabular}{cccc}
\hline Code & Question & Mean (Baseline) & Mean (Evaluation) \\
\hline BI & $\begin{array}{c}\text { Behavioral intention to save a substantial } \\
\text { amount of energy in the next three months at } \\
\text { respondent's workplace (a composite value) } \\
\text { I will try to save a substantial amount of energy } \\
\text { at work in the next three months }\end{array}$ & 4.06 & 4.69 \\
BI_1 & $\begin{array}{c}\text { I intend to save a substantial amount of energy } \\
\text { at work in the next three month }\end{array}$ & 4.09 & 4.02 \\
\hline
\end{tabular}

The results illustrated in Figure 4 and Table 8 provide evidence that the intervention promoted a solid positive change in Greek employees' personal norms. The overall score increased by 1.80 , from 3.76 to 5.56 .

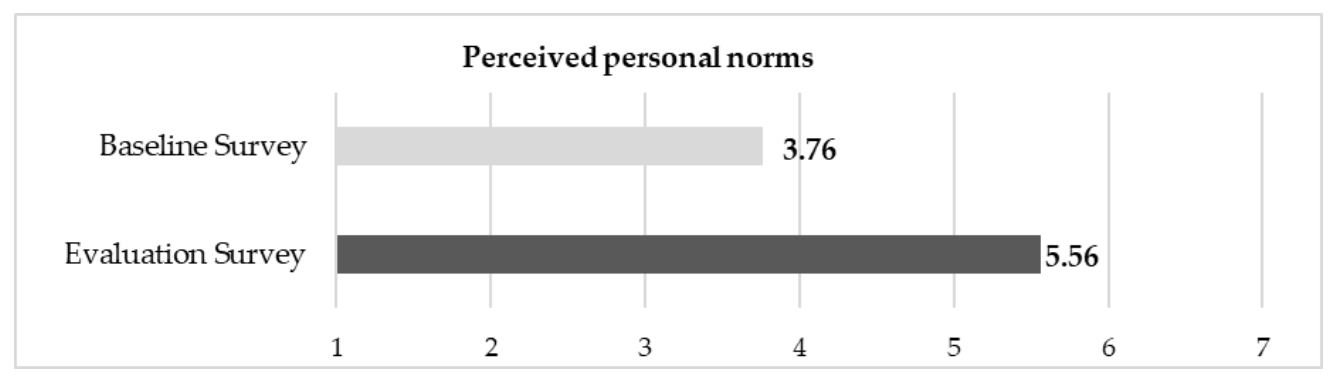

Figure 4. A comparison of perceived personal norms in Greek public buildings (before and after the trial).

It can be claimed that, at first, the employees of public buildings did not feel very morally obliged to save energy. Although the majority of them answered "completely agree" (7) to the questions about their personal norms, one-third of the respondents picked "totally disagree". After the trial was over, the respondents felt much more morally obliged to bear the environment in mind and to reduce their energy use, and they felt that this would lead to them becoming better people.

A high level of subjective norms can have a positive impact on one's intention to save energy. The overall score of this construct increased by 1.06, from 4.26 to 5.32 (see Figure 5). 


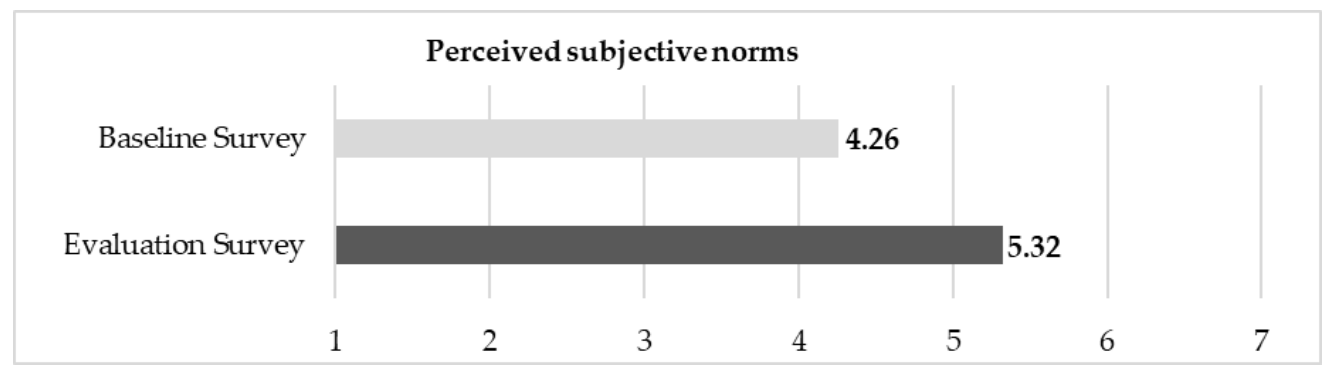

Figure 5. A comparison of perceived subjective norms in Greek public buildings (before and after the trial).

The answers to the baseline survey questions demonstrated that neither the superiors (4.50) nor the co-workers (4.56) or people who were important to the respondents' private lives (3.71) believed that the respondents should save energy at work. In contrast, after one year of intervention had passed, the subjective norm scores changed from negative/neutral to positive $(5.79,5.62$, and 4.55 , respectively; see Table 9).

Both the baseline and evaluation surveys contained a question regarding the energy-saving-comfort trade-off. The respondents had to indicate what is more important for them-feeling comfortable (1) or saving energy (7). It is worth noting that, even before the enCOMPASS trial started, the employees in the pilot study felt that saving energy was more important than feeling comfortable $(4,48)$. Therefore, it is not surprising that their opinions did not change a lot over the duration of the project (see Figure 6).

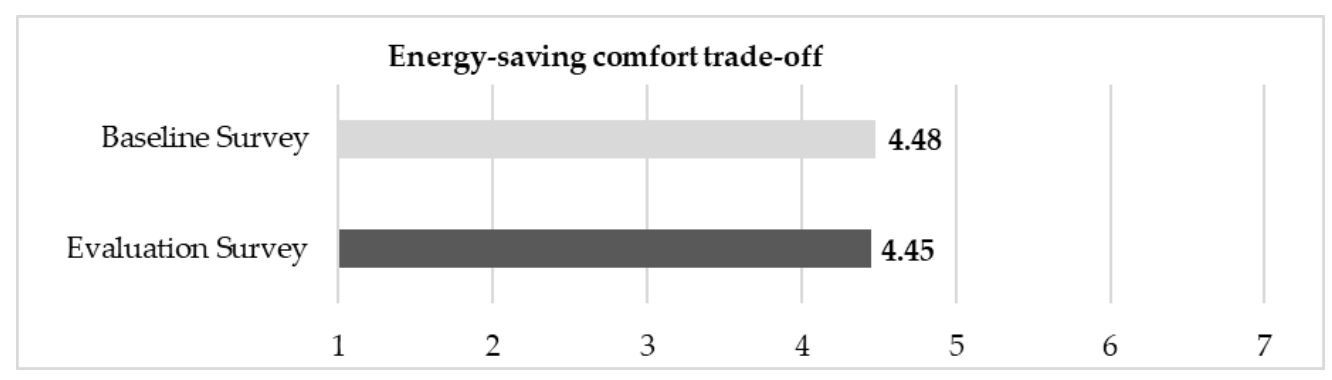

Figure 6. A comparison of energy-saving-comfort trade-off scores in Greek public buildings (before and after the trial).

\subsection{Knowledge}

The intervention also contributed to a positive effect on Greek pilot employees' energy consumption knowledge. The overall score of the construct increased by 0.78, from 3.14 to 3.92 (see Figure 7).

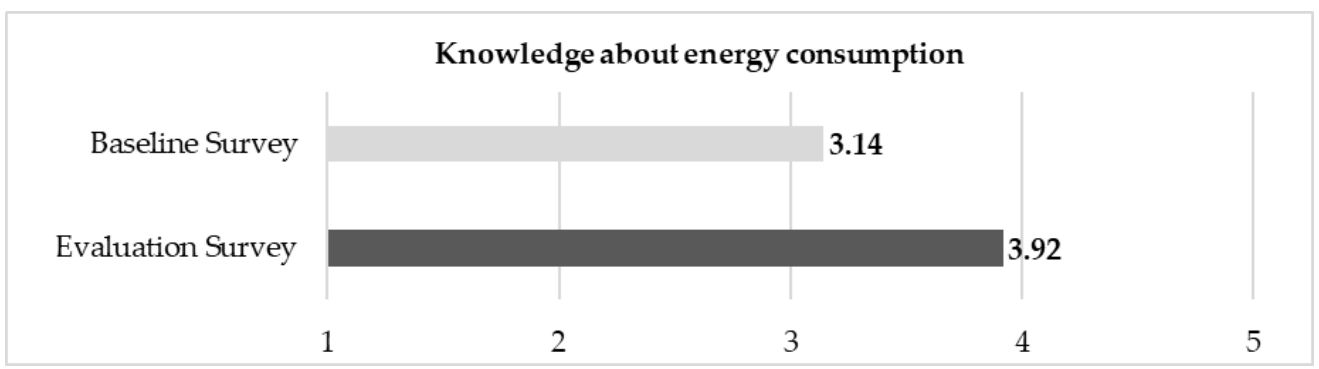

Figure 7. A comparison of energy-saving-comfort trade-off scores in Greek public buildings (before and after the trial).

It is evident that, over the period of a year, the participants in the trial increased their knowledge about energy consumption, especially regarding the amount of energy consumed by the surrounding 
lights and computers. Knowledge about the energy required for the heating system and air conditioning also expanded (the scores went from 3.07 to 3.79 and from 3.09 to 3.72, respectively).

In spite of having sufficient energy consumption knowledge (Figure 7), the score illustrating the control level the employees feel over power consumption at work decreased from 4.85 to 4.01 (see Figure 8).

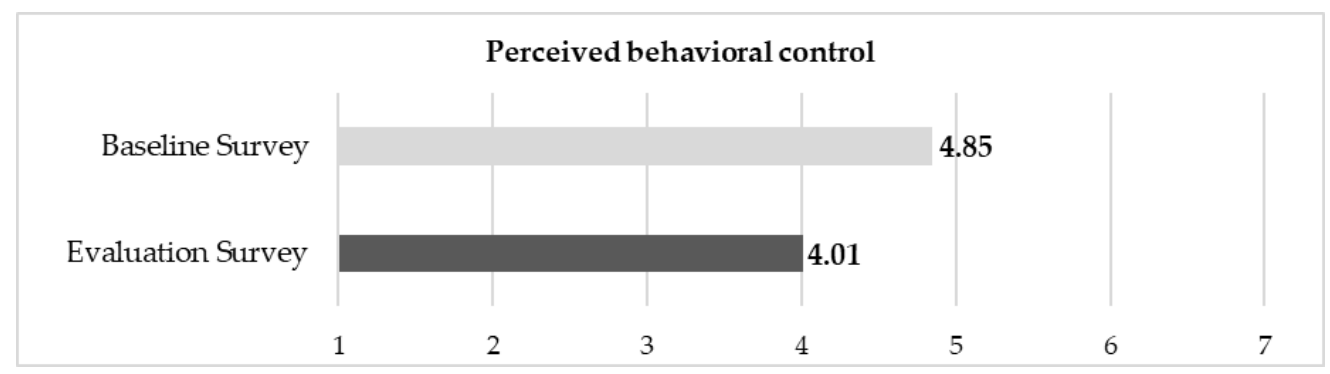

Figure 8. A comparison of the energy-saving-comfort trade-off in Greek public buildings (before and after the trial).

Though the respondents tended to believe that they are able to avoid unnecessary power consumption at work and limit their power consumption to the absolute necessary level, they stated that they strongly lack a feeling of control over the total amount of electricity consumed in their institution (see Table 11).

\subsection{Intention to Save Energy}

As Figure 9 demonstrates, at the beginning of the intervention, respondents were not very likely to have a strong behavioral intention to save energy in their workplace, as the mean of the answers was 4.06 (4 is "neutral"). When answering the evaluation survey questions, the respondents tended to agree with the statements, so the average score of this construct increased by 0.63 to 4.69 .

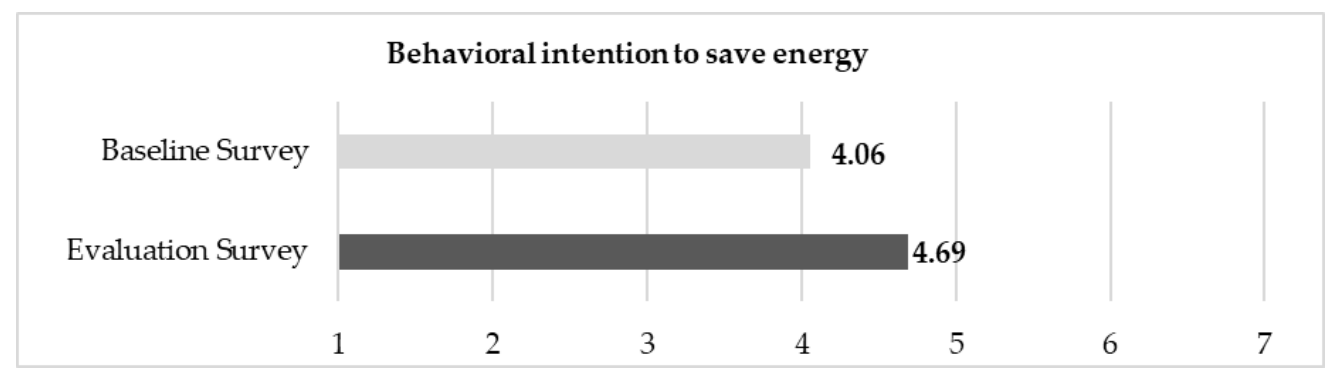

Figure 9. A comparison of behavioral intention to save energy scores in Greek public buildings (before and after trial).

As the answers reveal, the vast majority (72\%) of the trial participants stated that they try to save a substantial amount of energy at their workplace (average score 5.36). "Try" in this context means to make an attempt/effort to save energy. When we analyzed the answers to the second question about intention, which describes one's objective/plan to save energy, only $50 \%$ of the respondents picked the answers "somewhat agree", "mostly agree", and "completely agree" (average score 4.02 and it did not change over a year; see Table 12 for the comparison).

If we sum up the results of the baseline (first) questionnaire survey, we can see that, from the beginning of the intervention, saving energy was deemed to be more important than feeling comfortable. Furthermore, the respondents felt jointly responsible for energy problems and, even though their organization paid the energy bill, it was believed that saving as much energy as one could is important. However, the respondents did not have sufficient knowledge about the energy consumed by the surrounding electrical appliances. Moreover, neither the co-workers nor the superiors or other 
important people in the participants' private lives believed that they should save energy at work. Lastly, the participants of the trial stated that they did not feel morally obliged to bear the environment in mind and lacked a strong behavioral intention to save energy in their workplace.

During the intervention, the occupants of public buildings in Greece had the opportunity to expand their knowledge on how the devices they use daily consume energy and how they could build more energy-efficient habits (score increased by 0.78). They also improved their attitude towards energy saving in a positive way, and this project impacted not only the individuals, but also at the community level (the subjective norms score increased by 1.06 points). Other scores, such as the ascription of responsibility, personal norms towards energy reduction, and the intention to save energy, also increased (by $0.22,1.80$, and 0.63 , respectively).

On the other hand, the perceived behavioral control, which characterizes the level of control that a person feels over total unnecessary power consumption at work, decreased by 0.84 . However, this negative result might be explained by side factors. Once the intervention was over, the participants had more knowledge about energy consumption and might have started to understand that saving a considerable amount of energy requires both time and effort (the relationship between the constructs is investigated in the next section).

\subsection{Correlation Analysis}

All correlations that were significant at the 5\% and 1\% levels are presented in Tables 13 and 14 and discussed below.

The first correlation analysis was performed in order to find out whether respondents' socio-demographic features, that is, gender, age, and education level, are related to their ascription of responsibility, personal and subjective norms, perceived energy-saving-comfort trade-off, knowledge about energy saving, behavioral control, and intention to save energy at their workplace.

Table 13 illustrates that female employees feel more responsibility than males for energy problems, such as the exhaustion of energy sources or global warming $(0.267, p<0.05)$. Age, however, was found to be important when perceived behavioral control was analyzed. The results show that the older the person is, the more control he or she feels over limiting power consumption at work $(0.231, p<0.025)$. Quite surprisingly, the effect of education level was insignificant in this analysis.

In the comparison between the baseline and evaluation questionnaire surveys, the results of the construct "behavioral intention to save energy" were ambiguous; hence, this variable was later decomposed into two partially moderated variables: BI_1 “willingness to try to save a substantial amount of energy in the workplace" and BI_2 "an intention to save a substantial amount of energy in the workplace". Nevertheless, at this stage, no significant relationships were shown; therefore, the results are not included in Table 13.

Table 13. Correlation analysis (1).

\begin{tabular}{cccccccc}
\hline & AR & PN & SN & COMF & EN & PBC & BI \\
\hline \multirow{2}{*}{ Gender } & $0.267^{* *}$ & 0.065 & -0.01 & 0.071 & -0.045 & -0.004 & 0.103 \\
& 0.009 & 0.534 & 0.921 & 0.493 & 0.67 & 0.967 & 0.324 \\
Age & 0.096 & -0.088 & -0.196 & 0.111 & -0.033 & $0.231 *$ & 0.009 \\
& 0.356 & 0.397 & 0.058 & 0.285 & 0.759 & 0.025 & 0.93 \\
Education & 0.026 & -0.028 & 0.035 & -0.117 & 0.033 & -0.095 & -0.027 \\
level & 0.802 & 0.79 & 0.736 & 0.266 & 0.756 & 0.363 & 0.796 \\
\hline
\end{tabular}

** Correlation is significant at the 0.01 level (two-tailed). ${ }^{*}$ Correlation is significant at the 0.05 level (two-tailed). CC Sig., correlation coefficient's significance; AR, ascription of responsibility; PN, personal norms; $\mathrm{SN}$, subjective norm; COMF, comfort level; EN, knowledge about energy saving; PBC, perceived behavioral control; BI, behavioral intention.

The second correlation analysis checked the interrelations between the social and psychological determinants. 
The strongest relationship at the 0.01 significance level was found between the willingness to try to save a substantial amount of energy at the workplace and respondents' personal norms (BI_1/PN $0.463, p<0.01)$. The relationships with other constructs, such as subjective norms (BI_1/SN 0.203, $p<0.05$ ), energy-saving-comfort trade-off (BI_1/COMF 0.282, $p<0.01$ ), and energy-saving knowledge (BI_1/EN $0.369, p<0.01$ ) were also significant; hence, it was decided to perform a regression analysis that could reveal the exact predictors of the BI_1 variable that act as the most important outcomes of the intervention (see Section 4.5).

The results in Table 14 suggest that personal norms towards the reduction of energy use are related to almost every other analyzed construct. Here, we would like to emphasize that persons with high personal norms showed a higher preference for energy saving than comfort (PN/COMF 0.245, $p<0.05)$. The negative relationship between personal norms and perceived behavioral control $(-0.218$, $p<0.005)$ is quite an unexpected result, but it might be at least partially explained by the following point. Those respondents who feel more morally obliged to save energy than their co-workers already put in a greater effort to do so. Therefore, they may lack of a feeling of control over the total power consumption at their workplace.

To continue, a deeper knowledge about how much energy various surrounding electrical appliances consume can promote care for the environment and nature as well as changes in one's daily behavior (EN/PN 0.360, $p<0.01)$. Furthermore, this knowledge can determine the approach to the energy-saving-comfort trade-off (EN/COMF $0.344, p<0.01$ ) and motivate an individual to try to save a substantial amount of energy at work (EN/BI_1 $0.369, p<0.01)$.

Table 14. Correlation analysis (2).

\begin{tabular}{ccccccccc}
\hline & AR & PN & SN & COMF & EN & PBC & BI_1 & BI_2 \\
\hline \multirow{2}{*}{ AR } & 1 & $0.295^{* *}$ & 0.143 & $0.389^{* *}$ & 0.204 & 0.107 & 0.126 & -0.046 \\
& & 0.004 & 0.167 & 0 & 0.051 & 0.301 & 0.226 & 0.657 \\
PN & $0.295^{* *}$ & 1 & $0.344^{* *}$ & $0.245^{*}$ & $0.360^{* *}$ & $-0.218^{*}$ & $0.463 * *$ & -0.058 \\
& 0.004 & & 0.001 & 0.017 & 0 & 0.034 & 0 & 0.574 \\
SN & 0.143 & $0.344^{* *}$ & 1 & $0.208^{*}$ & 0.143 & -0.1 & $0.203^{*}$ & -0.044 \\
& 0.167 & 0.001 & & 0.044 & 0.173 & 0.336 & 0.05 & 0.675 \\
COMF & $0.389^{* *}$ & $0.245^{*}$ & $0.208^{*}$ & 1 & $0.344^{* *}$ & $0.312^{* *}$ & $0.282^{* *}$ & 0.051 \\
& 0 & 0.017 & 0.044 & & 0.001 & 0.002 & 0.006 & 0.621 \\
EN & 0.204 & $0.360^{* *}$ & 0.143 & $0.344^{* *}$ & 1 & $0.219 *$ & $0.369 * *$ & -0.078 \\
& 0.051 & 0 & 0.173 & 0.001 & & 0.036 & 0 & 0.457 \\
PBC & 0.107 & $-0.218^{*}$ & -0.1 & $0.312^{* *}$ & $0.219 *$ & 1 & 0.075 & -0.019 \\
& 0.301 & 0.034 & 0.336 & 0.002 & 0.036 & & 0.471 & 0.853 \\
BI_1 & 0.126 & $0.463^{* *}$ & $0.203 *$ & $0.282^{* *}$ & $0.369 * *$ & 0.075 & 1 & $0.356^{* *}$ \\
& 0.226 & 0 & 0.05 & 0.006 & 0 & 0.471 & & 0 \\
BI_2 & -0.046 & -0.058 & -0.044 & 0.051 & -0.078 & -0.019 & $0.356 * *$ & 1 \\
& 0.657 & 0.574 & 0.675 & 0.621 & 0.457 & 0.853 & 0 & \\
\hline
\end{tabular}

${ }^{* *}$ Correlation is significant at the 0.01 level (two-tailed). ${ }^{*}$ Correlation is significant at the 0.05 level (two-tailed). AR, ascription of responsibility; $\mathrm{PN}$, personal norms; $\mathrm{SN}$, subjective norm; COMF, comfort level; EN, knowledge about energy saving; PBC, perceived behavioral control; BI_1 "willingness to try to save a substantial amount of energy at work in the next three months" and BI_2 "an intention to save a substantial amount of energy at work in the next three months".

Finally, the results prove that the influence of other people plays an important role in the energy-saving process. It might affect one's personal norms towards the reduction of energy use; lead to an understanding that saving energy is more important than comfort; and, in addition to this, increase the willingness to try to save a substantial amount of energy (SN/PN $0.344, p<0.01$; SN/COMF $0.208, p<0.05 ;$ SN/BI_1 0.203, $p<0.05$ ). 


\subsection{Regression Analysis}

The stepwise linear regression method of regressing multiple variables while simultaneously removing those that are not relevant was used in the regression analysis.

The tables below (see Tables 15 and 16) present the key statistics of the final version of a multiple linear regression model. The insignificant variables-ascription of responsibility, perceived behavioral control, energy knowledge, subjective norms, and the energy-saving-comfort trade-off-were omitted. The results show that the predictor "personal norms towards the reduction of energy use" can explain $21.7 \%$ of the fluctuations in the dependent variable "willingness to try to save a substantial amount of energy at work in the next three months".

Table 15. Model summary.

\begin{tabular}{cccc}
\hline $\mathbf{R}$ & R Square & Adjusted R Square & Standard Error of the Estimate \\
\hline $0.475^{\mathrm{a}}$ & 0.226 & 0.217 & 1.283 \\
\hline
\end{tabular}

a. Predictors: (constant), PN.

Table 16. Final results of the statistical significance test.

\begin{tabular}{|c|c|c|c|c|c|c|c|}
\hline & \multicolumn{2}{|c|}{ Unstandardized Coefficients } & \multirow{2}{*}{$\begin{array}{c}\text { Standardized Coefficients } \\
\text { Beta }\end{array}$} & \multirow{2}{*}{$t$} & \multirow{2}{*}{ Sig. } & \multicolumn{2}{|c|}{ Collinearity Statistics } \\
\hline & B & Standard Error & & & & Tolerance & VIF \\
\hline (Constant) & 2.084 & 0.540 & & 3.859 & 0.000 & & \\
\hline PN & 0.569 & 0.112 & 0.475 & 5.090 & 0.000 & 1.000 & 1000 \\
\hline
\end{tabular}

Dependent variable: BI_1, willingness to try to save a substantial amount of energy at work in the next three months; PN, personal norms; VIF, variance inflation factor.

There was no multicollinearity (see Table 16$)$ between the independent variables $(1 \leq$ variance inflation factor $(\mathrm{VIF}) \leq 10)$; thus, the final proposed regression model equation is as follows:

$$
\mathrm{Y}_{\mathrm{BI} \_1}=2.084+0.569_{\mathrm{PN}} \text {. }
$$

Accordingly, a one point increase in the personal norms score results in an 0.569 point increase in BI_1, ceteris paribus. Therefore, it can be concluded that the willingness to save a substantial amount of energy at work is greater when employees feel morally obliged to consider the environment and nature in their daily behavior and believe that saving energy helps them to become a better person.

\section{Discussion}

The adoption of green practices [58,72] into business operations becomes an important issue in many organizations. The measures for energy efficiency could influence the reputation of organizations. Using various means of communication options to communicate environmental policy would then potentially improve employees' awareness of organizational efforts to promote energy efficiency. It is important for organizations to develop long-term strategies and to set quantifiable targets for energy saving [73]. The successful implementation of energy strategy includes a combination of the implementation of energy-efficient technology together with successful energy management practices. In this case, the employees with real ambition to improve energy efficiency in an organization are an important driving force implementing energy efficiency measures. The strategies for energy saving in organizations $[65,73]$ could include various interventions addressed to building users in order to change their behavior. Thus, the scientific literature pays more attention to the energy saving behavior of organizations.

The systematic literature review revealed some limitations of studies in the area concerned. Some articles were pretty narrow, analyzing only one aspect of energy saving possibilities, for example, Azizi et al. [65] focused on the energy consumption of a personal computer. Other studies were very 
specific because the results were influenced by climate or special governmental norms [19,61]. In some of the studies, the duration was too short to get more accurate results [11,16]. In other cases, for example, Schleich [13], data were collected from too many different companies, so the evaluation of energy consumption and saving patterns was complicated.

The limitations of this paper should also be mentioned. To begin with, only the behavior of the office staff was investigated. Furthermore, only one application of the energy saving method (intervention), as well as a limited number of respondents and a narrow geographical coverage (one country), were examined. On the other hand, most of these limitations appear owing to the financial constraints, as measures to promote savings and technology for energy consumption data acquisition and analytics require proper preparation and funding. We believe that the results of the empirical part of this article do not fully confirm the behavior of people in other countries because nations are culturally diverse and share different values, beliefs, attitudes, and behaviors. Furthermore, their approach towards energy consumption may be dissimilar as the climate zones, energy policies, and other important features can differ. Nevertheless, though the research was done within the framework of a project, the methodology itself may be applicable on a larger scale, hence there is a space for future research, which may be more detailed and applied across more buildings and countries. Further research could be important in making decisions about energy savings in offices as well as the visibility of pro-environmental values.

Another objective of further work could be to investigate the best treatments or actions to encourage energy savings in public buildings through behavioral change. Further research could examine the behavior of different employees as well as the possible impact of different levels of employee behavior. As the influence of visitors' behavior on energy consumption in public buildings was investigated in only one of the reviewed papers [20], there could be more research done on visitors' energy saving behavior.

\section{Conclusions}

Although the research of employees' behavior can give valuable insights into energy efficiency in public buildings, investment-intensive technological solutions are far more often investigated. Furthermore, most of the previous research conducted on efficient energy consumption behavior issues has focused on residential buildings. Therefore, this article considered the determinants that may influence energy-saving in public buildings. The determinants were classified into three main groups: (1) psychological and social determinants, (2) sociodemographic determinants, and (3) contextual determinants. The first two groups are called the individual predictors, while the third group, the contextual determinants, represents the factors that may have an external influence on energy saving behavior, and thus are called situational predictors.

The research question of the systematic literature review was "which determinants of energy consumption in public buildings are most studied in the scientific literature?" After the investigation of all individual and situational predictors influencing energy saving behavior in public buildings, it can be summarized that the most investigated group of determinants is "psychological and social determinants". The most researched and scientifically proven determinants of energy-saving behavior in public buildings are related to psychological and social backgrounds. These are (1) attitudes, (2) awareness, (3) social (personal) norms, (4) knowledge, (5) subjective norms, and (6) motivation.

As the above-mentioned determinants can have an impact on energy-saving behavior, an empirical research question was "how an intervention, based on stimulation of key psychological and social determinants, affects the behavior of employees of public buildings?" The answers to the baseline and evaluation questionnaire surveys showed how a one-year intervention in public buildings in Greece changed the levels of the determinants. The results show that the occupants of public buildings had the opportunity to expand their knowledge on how the devices they use daily consume energy and how they can build more energy-efficient habits. They also improved their attitudes towards energy saving in a positive way. Other scores, such as those related to subjective and personal norms, ascription 
of responsibility, and intention to save energy, also increased. Therefore, it proves the potential of gamified intervention, which acts as an incentive towards positive energy-saving behavioral change.

A correlation analysis revealed that the influence of other people plays a significant role in the energy-saving process. It might affect one's personal norms towards the reduction of energy use and lead to the understanding that saving energy is more important than comfort. Furthermore, the results show that female employees feel more responsibility than males regarding energy problems, such as the exhaustion of energy sources or global warming. To continue with, age was shown to be important when talking about perceived behavioral control and that, the older the person is, the more control he or she feels over limiting power consumption at work. Quite surprisingly, education level was shown to be insignificant. Finally, a regression analysis demonstrated that the willingness to save a substantial amount of energy at work is greatest when employees have higher levels of personal norms, that is, they feel morally obliged to consider the environment and nature in their daily behavior.

In conclusion, the results of an empirical investigation show the following: (1) there is a significant positive relationship between one's personal norms (PN), subjective norms (SN), knowledge about energy saving (EN), and the behavioral intention to save it; and (2) intervention was successful in changing these constructs (i.e., over the year, the overall score of PN increased by 1.80 (from 3.76 to 5.56), $\mathrm{SN}$ increased by 1.06 (from 4.26 to 5.32), and EN increased by 0.78 (from 3.14 to 3.92). The results of both the systematic literature review and the survey may thus be applied during the consideration of interventions for employees and users of public buildings to encourage energy-saving behaviors.

Author Contributions: Conceptualization: D.D. and A.C.; methodology: D.D., A.C., and M.A.; software: M.A.; validation: D.D., A.C., and M.A.; investigation: D.D., A.C., and M.A.; supervision: D.D.; writing and review: D.D., A.C., and M.A. All authors have read and agreed to the published version of the manuscript.

Funding: This work was partially supported by the "enCOMPASS-Collaborative Recommendations and Adaptive Control for Personalized Energy Saving" project funded by the EU H2020 Programme under grant agreement no. 723059 .

Conflicts of Interest: The authors declare no conflict of interest. The funders had no role in the design of the study; in the collection, analyses, or interpretation of data; in the writing of the manuscript; or in the decision to publish the results.

\section{References}

1. Daily, B.F.; Huang, S.C. Achieving sustainability through attention to human resource factors in environmental management. Int. J. Oper. Prod. Manag. 2001, 21, 1539-1552. [CrossRef]

2. Ruparathna, R.; Hewage, K.; Sadiq, R. Improving the energy efficiency of the existing building stock: A critical review of commercial and institutional buildings. Renew. Sustain. Energy Rev. 2016, 53, 1032-1045. [CrossRef]

3. Bull, R.; Lemon, M.; Everitt, D.; Stuart, G. Moving beyond feedback: Energy behaviour and local engagement in the United Kingdom. Energy Res. Soc. Sci. 2015, 8, 32-40. [CrossRef]

4. Carbon Trust. Catalysing Investment in the Low Carbon Economy. 2009. Available online: https: //www.carbontrust.com/media/263294/ctc778-annual-review-2009-10.pdf (accessed on 7 May 2019).

5. Manika, D.; Gregory-Smith, D.; Wells, V.K.; Graham, S. Home vs. workplace energy saving attitudes and behaviors: The moderating role of satisfaction with current environmental behaviors, gender, age, and job duration. In Proceedings of the 2015 Winter Marketing Educators' Conference-Marketing in a Global, Digital and Connected World, San Antonio, TX, USA, 13-15 February 2015.

6. EIA, U.S. Annual Energy Review. Energy Information Administration; US Department of Energy: Washington, DC, USA, 2011. Available online: https://www.eia.doe.gov/emeu/aer (accessed on 13 October 2019).

7. PC Energy Report 2009, USA, United Kingdom, Germany. Available online: https://www. climatesaverscomputing.org/wordpress/wp-content/uploads/2011/06/1E_PC_Energy_Report_2009_US.pdf (accessed on 15 November 2019).

8. Murtagh, N.; Nati, M.; Headley, W.R.; Gatersleben, B.; Gluhak, A.; Imran, M.A.; Uzzell, D. Individual energy use and feedback in an office setting: A field trial. Energy Policy 2013, 62, 717-728. [CrossRef] 
9. Mulville, M.; Jones, K.; Huebner, G. The potential for energy reduction in UK commercial offices through effective management and behaviour change. Archit. Eng. Des. Manag. 2014, 10, 79-90. [CrossRef]

10. Masoso, O.T.; Grobler, L.J. The dark side of occupants' behaviour on building energy use. Energy Build. 2010, 42, 173-177. [CrossRef]

11. Yun, G.Y.; Kong, H.J.; Kim, H.; Kim, J.T. A field survey of visual comfort and lighting energy consumption in open plan offices. Energy Build. 2012, 46, 146-151. [CrossRef]

12. Salleh, M.N.M.; Kandar, M.Z.; Sakip, S.R.M. Benchmarking for Energy Efficiency on School Buildings Design: A Review. Procedia-Soc. Behav. Sci. 2016, 222, 211-218. [CrossRef]

13. Schleich, J. Barriers to energy efficiency: A comparison across the German commercial and services sector. Ecol. Econ. 2009, 68, 2150-2159. [CrossRef]

14. Yun, R. Persistent workplace plug-load energy savings and awareness through energy dashboards: Eco-feedback, control, and automation. In CHI'14 Extended Abstracts on Human Factors in Computing Systems; Association for Computing Machinery: New York, NY, USA, 2014; pp. 331-334. Available online: https://dl.acm.org/doi/10.1145/2559206.2559961 (accessed on 10 June 2017).

15. Katzeff, C.; Broms, L.; Jönsson, L.; Westholm, U.; Räsänen, M. Exploring Sustainable Practices in Workplace Settings Through Visualizing Electricity Consumption. ACM Trans. Comput. Hum. Interact. 2013, 20, 31:1-31:22.

16. Agha-Hossein, M.M.; Tetlow, R.M.; Hadi, M.; El-Jouzi, S.; Elmualim, A.A.; Ellis, J.; Williams, M. Providing persuasive feedback through interactive posters to motivate energy-saving behaviours. Intell. Build. Int. 2015, 7, 16-35. [CrossRef]

17. Nilsson, A.; Andersson, K.; Bergstad, C.J. Energy behaviors at the office: An intervention study on the use of equipment. Appl. Energy 2015, 146, 434-441. [CrossRef]

18. Scherbaum, C.A.; Popovich, P.M.; Finlinson, S. Exploring Individual-Level Factors Related to Employee Energy-Conservation Behaviors at Work. J. Appl. Soc. Psychol. 2008, 38, 818-835. [CrossRef]

19. Zhang, Y.; Wang, Z.; Zhou, G. Antecedents of employee electricity saving behavior in organizations: An empirical study based on norm activation model. Energy Policy 2013, 62, 1120-1127. [CrossRef]

20. Jáñez Morán, A.; Profaizer, P.; Herrando Zapater, M.; Andérez Valdavida, M.; Zabalza Bribián, I. Information and Communications Technologies (ICTs) for energy efficiency in buildings: Review and analysis of results from EU pilot projects. Energy Build. 2016, 127, 128-137. [CrossRef]

21. Yan, D.; Hong, T.; Dong, B.; Mahdavi, A.; D’Oca, S.; Gaetani, I.; Feng, X. IEA EBC Annex 66: Definition and simulation of occupant behavior in buildings. Energy Build. 2017, 156, 258-270. [CrossRef]

22. Liang, J.; Qiu, Y.; Hu, M. Mind the energy performance gap: Evidence from green commercial buildings. Resour. Conserv. Recycl. 2019, 141, 364-377. [CrossRef]

23. Jakubiec, J.A.; Reinhart, C.F. The 'adaptive zone'-A concept for assessing discomfort glare throughout daylit spaces. Lighting Res. Technol. 2012, 44, 149-170. [CrossRef]

24. Schweiker, M.; Wagner, A. The effect of occupancy on perceived control, neutral temperature, and behavioral patterns. Energy Build. 2016, 117, 246-259. [CrossRef]

25. Ajzen, I.; Fishbein, M. Attitude-behavior relations: A theoretical analysis and review of empirical research. Psychol. Bull. 1977, 84, 888. [CrossRef]

26. Stern, P.C. What psychology knows about energy conservation. Am. Psychol. 1992, 47, 1224. [CrossRef]

27. Abrahamse, W.; Steg, L. Factors related to household energy use and intention to reduce it: The role of psychological and socio-demographic variables. Hum. Ecol. Rev. 2011, 18, 30-40.

28. Chen, C.F.; Knight, K. Energy at work: Social psychological factors affecting energy conservation intentions within Chinese electric power companies. Energy Res. Soc. Sci. 2014, 4, 23-31. [CrossRef]

29. D'Oca, S.; Corgnati, S.; Pisello, A.L.; Hong, T. Introduction to an Occupant Behavior Motivation Survey Framezork; Lawrence Berkeley National Laboratory: Berkely, CA, USA, 2016.

30. Greaves, M.; Zibarras, L.D.; Stride, C. Using the theory of planned behavior to explore environmental behavioral intentions in the workplace. J. Environ. Psychol. 2013, 34, 109-120. [CrossRef]

31. Nisiforou, O.A.; Poullis, S.; Charalambides, A.G. Behaviour, attitudes and opinion of large enterprise employees with regard to their energy usage habits and adoption of energy saving measures. Energy Build. 2012, 55, 299-311. [CrossRef] 
32. Ucci, M.; Domenech, T.; Ball, A.; Whitley, T.; Wright, C.; Mason, D.; Westaway, A. Behaviour change potential for energy saving in non-domestic buildings: Development and pilot-testing of a benchmarking tool. Build. Serv. Eng. Res. Technol. 2014, 35, 36-52. [CrossRef]

33. Zierler, R.; Wehrmeyer, W.; Murphy, R. The energy efficiency behaviour of individuals in large organisations: A case study of a major UK infrastructure operator. Energy Policy 2017, 104, 38-49. [CrossRef]

34. Lo, S.H.; Peters, G.-J.Y.; Kok, G. Energy-Related Behaviors in Office Buildings: A Qualitative Study on Individual and Organisational Determinants. Appl. Psychol. Int. Rev. 2012, 61, 227-249. [CrossRef]

35. Carrico, A.R.; Riemer, M. Motivating energy conservation in the workplace: An evaluation of the use of group-level feedback and peer education. J. Environ. Psychol. 2011, 31, 1-13. [CrossRef]

36. Moher, D.; Shamseer, L.; Clarke, M.; Ghersi, D.; Liberati, A.; Petticrew, M.; Stewart, L.A. Preferred reporting items for systematic review and meta-analysis protocols (PRISMA-P) 2015 statement. Syst. Rev. 2015, 4, 1. [CrossRef]

37. Armstrong, R.; Hall, B.J.; Doyle, J.; Waters, E. Scoping the scope'of a cochrane review. J. Public Health 2011, 33, 147-150. [CrossRef]

38. Dewey, A.; Drahota, A. Introduction to Systematic Reviews: Online Learning Module Cochrane Training. Available online: https:/training.cochrane.org/interactivelearning/module-1-introduction-conductingsystematic-reviews (accessed on 24 October 2019).

39. Frederiks, E.R.; Stenner, K.; Hobman, E.V. Household energy use: Applying behavioral economics to understand consumer decision-making and behavior. Renew. Sustain. Energy Rev. 2015, 41, 1385-1394. [CrossRef]

40. Agha-Hossein, M.M.; El-Jouzi, S.; Elmualim, A.A.; Ellis, J.; Williams, M. Post-occupancy studies of an office environment: Energy performance and occupants' satisfaction. Build. Environ. 2013, 69, 121-130. [CrossRef]

41. Christina, S.; Dainty, A.; Daniels, K.; Waterson, P. How organisational behaviour and attitudes can impact building energy use in the UK retail environment: A theoretical framework. Archit. Eng. Des. Manag. 2014, 10, 164-179. [CrossRef]

42. Handgraaf, M.J.J.; Van Lidth de Jeude, M.A.; Appelt, K.C. Public praise vs. private pay: Effects of rewards on energy conservation in the workplace. Ecol. Econ. 2013, 86, 86-92. [CrossRef]

43. Lokhorst, A.; Staats, H.; Iterson, J. Energy Saving in Office Buildings: Are Feedback and Commitment-Making Useful Instruments to Trigger Change? Hum. Ecol. Interdiscip. J. 2015, 43, 759-768. [CrossRef]

44. Loureiro, A.; Lima, M.L. Energy Saving Behaviour in an Organisational Context; ECEEE; Lisbon University Institute: Lisbon, Portugal, 2009.

45. Tetlow, R.M.; van Dronkelaar, C.; Beaman, C.P.; Elmualim, A.A.; Couling, K. Identifying behavioural predictors of small power electricity consumption in office buildings. Build. Environ. 2015, 92, 75-85. [CrossRef]

46. Wells, V.K.; Taheri, B.; Gregory-Smith, D.; Manika, D. The role of generativity and attitudes on employees home and workplace water and energy saving behaviours. Tour. Manag. 2016, 56, 63-74. [CrossRef]

47. Xu, X.; Maki, A.; Chen, C.F.; Dong, B.; Day, J.K. Investigating willingness to save energy and communication about energy use in the American workplace with the attitude-behavior-context model. Energy Res. Soc. Sci. 2017. [CrossRef]

48. Schwartz, S.H. Normative influences on altruism. In Advances in Experimental Social Psychology; Academic: New York, NY, USA, 1977; pp. 221-279.

49. Thøgersen, J.; Grønhøj, A. Electricity saving in households-A social cognitive approach. Energy Policy 2010, 38, 7732-7743. [CrossRef]

50. Ajzen, I. The theory of planned behavior. Organ. Behav. Hum. Decis. Process. 1991, 50, 179-211. [CrossRef]

51. Steg, L.; Dreijerink, L.; Abrahamse, W. Factors influencing the acceptability of energy policies: A test of VBN theory. J. Personal. Soc. Psychol. 2005, 25, 415-425. [CrossRef]

52. Stern, P.C. New environmental theories: Toward a coherent theory of environmentally significant behavior. J. Soc. Issues 2000, 56, 407-424. [CrossRef]

53. Stokes, L.C.; Mildenberger, M.; Savan, B.; Kolenda, B. Analyzing Barriers to Energy Conservation in Residences and Offices: The Rewire Program at the University of Toronto. Appl. Environ. Educ. Commun. 2012, 11, 88-98. [CrossRef]

54. Jurin, R.R.; Fox-Parrish, L. Factors in Helping Educate about Energy Conservation. Appl. Environ. Educ. Commun. 2008, 7, 66-75. [CrossRef] 
55. Lee, L.-S.; Lin, K.-Y.; Guu, Y.-H.; Chang, L.-T.; Lai, C.-C. The effect of hands-on "energy-saving house" learning activities on elementary school students' knowledge, attitudes, and behavior regarding energy saving and carbon-emissions reduction. Environ. Educ. Res. 2013, 19, 620-638. [CrossRef]

56. Manika, D.; Wells, V.; Gregory-Smith, D.; Gentry, M. The Impact of Individual Attitudinal and Organisational Variables on Workplace Environmentally Friendly Behaviours. J. Bus. Ethics 2015, 126, 663-684. [CrossRef]

57. Gustafson, C.; Longland, M.; Hydro, B.C. Engaging employees in conservation leadership. In Proceedings of the 2008 ACEEE Summer Study on Energy Efficiency in Buildings, American Council for and Energy-Efficient Economy, Washington, DC, USA, 29 August 2008; Available online: https://www.aceee.org/files/proceedings/ 2008/data/papers/7_532.pdf\#page=1 (accessed on 20 June 2017).

58. Sawang, S.; Kivits, R.A. Greener workplace: Understanding senior management's adoption decisions through the Theory of Planned Behaviour. Australas. J. Environ. Manag. 2014, 21, 22-36. [CrossRef]

59. Pellegrini-Masini, G.; Leishman, C. The role of corporate reputation and employees' values in the uptake of energy efficiency in office buildings. Energy Policy 2011, 39, 5409-5419. [CrossRef]

60. Tolias, E.; Costanza, E.; Rogers, A.; Bedwell, B.; Banks, N. IdleWars: An evaluation of a pervasive game to promote sustainable behaviour in the workplace. In International Conference on Entertainment Computing; Springer: Cham, Germany, 2015; pp. 224-237.

61. Zhuang, X.; Wu, C. Saving energy when using air conditioners in offices-Behavioral pattern and design indications. Energy Build. 2014, 76, 661-668. [CrossRef]

62. Metzger, I.; Kandt, A.; VanGeet, O. Plug Load Behavioral Change Demonstration Project; No. NREL/TP-7A40-52248; National Renewable Energy Laboratory (NREL): Golden, CO, USA, 2011.

63. DiMatteo, J.; Radnitz, C.; Zibulsky, J.; Brown, J.; Deleasa, C.; Jacobs, S. Is Energy Conservation Education Effective? An Evaluation of the PowerSave Schools Program. Appl. Environ. Educ. Commun. 2014, 13, 99-108. [CrossRef]

64. Karatas, A.; Stoiko, A.; Menassa, C.C. Framework for selecting occupancy-focused energy interventions in buildings. Build. Res. Inf. 2016, 44, 535-551. [CrossRef]

65. Azizi, N.S.M.; Wilkinson, S.; Fassman, E. Strategies for improving energy saving behaviour in commercial buildings in Malaysia. Eng. Constr. Archit. Manag. 2015, 22, 73-90. [CrossRef]

66. Henriques, J.; Catarino, J. Motivating towards energy efficiency in small and medium enterprises. J. Clean. Prod. 2016, 139, 42-50. [CrossRef]

67. Chung, W.; Hui, Y.V. A study of energy efficiency of private office buildings in Hong Kong. Energy Build. 2009, 41, 696-701. [CrossRef]

68. Li, C.; Hong, T.; Yan, D. An insight into actual energy use and its drivers in high-performance buildings. Appl. Energy 2014, 131, 394-410. [CrossRef]

69. Schleich, J.; Gruber, E. Beyond case studies: Barriers to energy efficiency in commerce and the services sector. Energy Econ. 2008, 30, 449-464. [CrossRef]

70. Fabi, V.; Andersen, R.V.; Corgnati, S.; Olesen, B.W. Occupants' window opening behaviour: A literature review of factors influencing occupant behaviour and models. Build. Environ. 2012, 58, 188-198. [CrossRef]

71. Goulden, M.; Spence, A. Caught in the middle: The role of the Facilities Manager in organisational energy use. Energy Policy 2015, 85, 280-287. [CrossRef]

72. Schelly, C.; Cross, J.E.; Franzen, W.S.; Hall, P.; Reeve, S. Reducing Energy Consumption and Creating a Conservation Culture in Organizations: A Case Study of One Public School District. Environ. Behav. 2010, 43, 316-343. [CrossRef]

73. Johansson, M.T.; Thollander, P. A review of barriers to and driving forces for improved energy efficiency in Swedish industry-Recommendations for successful in-house energy management. Renew. Sustain. Energy Rev. 2018, 82, 618-628. [CrossRef]

(C) 2020 by the authors. Licensee MDPI, Basel, Switzerland. This article is an open access article distributed under the terms and conditions of the Creative Commons Attribution (CC BY) license (http://creativecommons.org/licenses/by/4.0/). 